\title{
XQUESTION: Um sistema pessoal de resposta para decisões estratégicas do professor durante uma aula
}

\author{
Adilmar C. Dantas ${ }^{1}$, Hermes G. Neri ${ }^{1}$, Eduardo K. Takahashi ${ }^{1}$, Márcia A. Fernandes ${ }^{1}$ \\ ${ }^{1}$ Departamento de Ciência da Computação \\ Universidade Federal de Uberlândia \\ Uberlândia - Minas Gerais - Brasil \\ email\{akanehar,ektakahashi,hermesneri\}@gmail.com,marcia@ufu.br
}

\begin{abstract}
This work shows a personal response software that enables teachers to make strategic decisions during a class. Students record their answers to questions previously formulated through the applicative and teachers can monitor their answers and assess in real time the need or not for complementary strategies for understanding topics under study. Its low cost gives him an advantage over the clicker device.
\end{abstract}

Resumo. Este trabalho apresenta um software educacional pessoal de resposta para decisões estratégicas do professor durante uma aula. Os estudantes respondem questões previamente formuladas e o professor pode acessar suas respostas por meio do aplicativo e avaliar a necessidade ou não de estratégias complementares para o entendimento do tópico em estudo. O baixo custo do aplicativo é sua vantagem em relação aos dispositivos clickers.

\section{Introdução}

Os sistemas pessoais de resposta (personal response systems), também conhecidos por clickers ou response pulses, são dispositivos tecnológicos semelhantes a controles remotos de TV, contendo, em geral, um teclado numérico e alguns botões de controle. Eles permitem que o aluno responda, de forma rápida, questões apresentadas pelo professor durante uma aula expositiva-dialogada. O software de controle desse dispositivo possibilita ao professor obter rapidamente a estatística das respostas da sala, o que permite um feedback imediato da compreensão da matéria pelo aluno e, através disso, tomar decisões acerca do andamento da aula. Com o surgimento de novas tecnologias da informação surgiram inúmeras possibilidades para a educação. O próprio avanço da rede mundial de computadores e da rápida propagação da informação tornaram professores e alunos cada vez mais bem informados e conectados digitalmente [Mercado 2002], através de sistemas computacionais.

O uso desse tipo de tecnologia promove a aprendizagem ativa, pois utilizam de práticas pedagógicas,nas quias do aluno o aluno deixa de exercer somente o papel de "recebedor"de informações, pois será inserido em um ambiente onde deve ser construtor dos seus conhecimentos de maneira proativa. Os benefícios proporcionados pela aprendizagem ativa são facilmente alcançados, principalmente no ensino superior [Martyn 2007], onde a maioria dos alunos faz uso dos mais modernos recursos tecnológicos para buscar o conhecimento. Entretanto, tais dispositivos apresentam os seguintes incômodos: são altamente dependentes do hardware, não exibem dados estatísticos na forma gráfica, exige a transcrição manual dos dados pelo professor para outra plataforma, não permitem 
V Congresso Brasileiro de Informática na Educação (CBIE 2016)

Anais dos Workshops do V Congresso Brasileiro de Informática na Educação (CBIE 2016)

a comunicação entre clickers de marcas diferentes, exigem manutenção permanente e é necessária uma vigilância desses dispositivos, pelo professor, para evitar perdas e danos.

Para contornar essas dificuldades, desenvolvemos uma aplicação mobile, denominada XQuestion, utilizando tecnologias web que permitem que a aplicação seja renderizada em diversos dispositivos, tais como: smartphone, desktop e notebooks em geral, independente do sistema operacional. Assim o aplicativo permite a integração entre diferentes dispositivos e o estudante poderá fazer uso do seu próprio dispositivo tecnológico de informação e comunicação. Além disso, contém uma parte administrativa que permite ao docente o acesso à estatística das respostas em forma gráfica, pois ele armazena as respostas em uma base de dados que pode ser gerenciada pelo professor, ou pela instituição.

\section{XQuestion software multiplataforma}

O Xquestion foi projetado utilizando tecnologias atuais, permitindo uma maior usabilidade do sistema em ambientes educacionais. Para o seu desenvolvimento foram utilizadas tecnologias como Jquery Mobile, que consiste em um sistema de interface baseado no HTML5, possibilitando a criação de aplicações acessíveis [jQuery 2016], sendo possível sua execução em qualquer dispositivo. Esse tipo de aplicação é hoje denominado como responsivos, possuindo a capacidade de se adaptar a qualquer plataforma. A Tabela 1 ilustra a execução do aplicativo desenvolvido em diferentes dispositivos.

\begin{tabular}{|c|c|c|c|}
\hline & Navegador & Versões & Resultado \\
\hline & Google Chrome & 52.0 & Funcional \\
\hline & Mozilla Firefox & 47.00 & Funcional \\
\hline & Internet Explorer & 11 & Com limitações \\
\hline & Safari & 5.1 .7 & Funcional \\
\hline & Android & 2.0 até 6.0 & Funcional \\
\hline & $\mathrm{iOS}$ & 5.0 até 8.0 & Funcional \\
\hline
\end{tabular}

A aplicação desenvolvida conta com dois módulos principais: um para o aluno e outro para o professor ou tutor. Na interface do aluno encontram-se as informações para o acesso dos estudantes, onde ele deve selecionar o respectivo curso, em seguida o questionamento abordado e então entrar com sua resposta no mesmo formato oferecido pelos dispositivos cliker físicos, através de quatro opções (A,B,C,D) no formado múltipla escolha, conforme a Figura 1.

O acesso ao questionário permanece constantemente liberado para os estudantes até que o professor ou tutor remova o mesmo do aplicativo. A interface do professor é responsável pelo gerenciamento da aplicação, onde estão disponíveis as seguintes funcionalidades: adicionar curso, adicionar questionamento e a mais importante delas, gerar gráficos estatísticos em tempo real referentes as respostas dos alunos durante a aula, conforme a figura 2.

Ao responder os questionamentos, as respostas são processadas pelo servidor da aplicação, que realiza seu devido armazenamento na base de dados. Para o banco de 
V Congresso Brasileiro de Informática na Educação (CBIE 2016)

Anais dos Workshops do V Congresso Brasileiro de Informática na Educação (CBIE 2016)

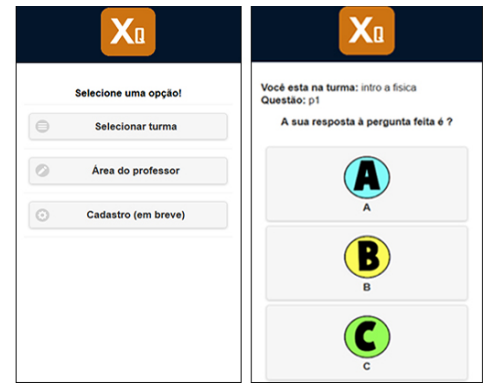

Figura 1. Xquestion módulo aluno, com cliker virtual. Fonte: $\mathrm{O}$ autor

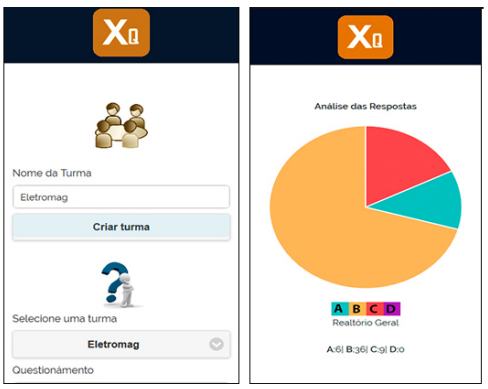

Figura 2. Xquestion módulo professor, com geração de relatórios.

Fonte: O autor

dados, utilizou-se o banco Mysql, um banco de dados de código aberto mais utilizado no mundo [Mysql 2016], sendo o líder, atualmente, para aplicações web. O armazenamento e apresentação das respostas visualmente é altamente relevante, pois é com base nela que o professor é capaz de avaliar ou não a necessidade de alguma decisão estratégica para melhorar a aprendizagem durante a aula. Para que fosse possível avaliar as principais vantagens deste tipo de sistema sobre os Clikers físicos, foi elaborada a Tabela 2, que apresenta as principais características dos Clikers Hardware e Software.

Tabela 2. Comparativo Software Cliker e Cliker Hardware

\begin{tabular}{|c|c|c|}
\hline Características & Cliker Software & Cliker Hardware \\
\hline Portabilidade & Sim. & Sim. \\
\hline Aquisição de Hardware & $\begin{array}{l}\text { Não, os hardwares são os próprios } \\
\text { dispositivos dos alunos e professor. }\end{array}$ & Sim um Cliker por aluno. \\
\hline Monitoramento do Hardware & $\begin{array}{l}\text { Não, existe esta necessidade pois cada } \\
\text { usuário é dono de seu aparelho. }\end{array}$ & $\begin{array}{l}\text { Sim, os aparelhos pertencem às instituições } \\
\text { de ensino, necessitando de monitoramento } \\
\text { durante o uso. }\end{array}$ \\
\hline Multiplataforma & $\begin{array}{l}\text { Sim, permite a execução em desktop, tablet, } \\
\text { e qualquer aparelho móvel. }\end{array}$ & $\begin{array}{l}\text { Não, na maioria das vezes existem apenas } \\
\text { alguns modelos que permitem uso em desktop. }\end{array}$ \\
\hline Personalização & $\begin{array}{l}\text { Sim, o professor pode personalizar seus } \\
\text { relatórios de acordo com suas necessidades. }\end{array}$ & $\begin{array}{l}\text { Não, geralmente os dados são apresentados de } \\
\text { uma única maneira sem muita personalização. }\end{array}$ \\
\hline Conexão & $\begin{array}{l}\text { Sim, para que seja possível acessar a aplicação } \\
\text { é necessário uma conexão com internet. }\end{array}$ & $\begin{array}{l}\text { Não, nenhum tipo de conexão externa é } \\
\text { necessária. }\end{array}$ \\
\hline
\end{tabular}

Observando a Tabela 2, nota-se que na maioria das caraterísticas o software possui vantagens, aumentando a produtividade e reduzindo principalmente os custos, colaborando assim de maneira significativa para a utilização dessa tecnologia no processo de ensino e aprendizagem. 
V Congresso Brasileiro de Informática na Educação (CBIE 2016)

Anais dos Workshops do V Congresso Brasileiro de Informática na Educação (CBIE 2016)

\section{Testes e Validação do Sistema}

O uso do software Xquestion foi feito em uma turma de 51 estudantes da disciplina Introdução à Física, do curso de Licenciatura em Física em uma Universidade Federal. Ao abordar o tema "Modelo Atômico de Bohr", os estudantes foram solicitados a responder 6 testes durante a aula, cujas respostas foram registradas pelos estudantes no aplicativo e avaliadas em tempo real pelo professor da disciplina.

As questões foram projetadas em tela durante a aula, de forma sequencial, e as respostas serviram de avaliação do grau de compreensão da sala sobre o tema. Respostas certas em porcentagem igual ou acima de $70 \%$ foram consideradas plenamente satisfatórias, enquanto $30 \%$ ou menos de respostas corretas foram consideradas muito problemáticas e alguma estratégia complementar foi adotada para procurar sanar as dúvidas dos alunos. Porcentagens intermediárias de acertos resultaram em discussões coletivas até a obtenção de um consenso. Cada teste foi analisado imediatamente após a obtenção das percentagens de acertos. Da análise dos percentuais das respostas, obtivemos que 70,6\% dos alunos acertaram o teste 1 (resposta b), 84,1\% acertaram o teste 2 (resposta c), 64,4\% acertaram o teste 3 (resposta b), 77,1\% acertaram o teste 4 (resposta a), 39,5\% acertaram o teste 5 (resposta a) e 56,4\% acertaram o teste 6 (resposta c).

Assim, os conteúdos dos testes 1, 2 e 4 foram apenas generalizados, uma vez que apresentaram índices plenamente satisfatórios. Os testes 3, 5 e 6 receberam tratamentos mais cuidadosos por parte do professor e foram travadas discussões envolvendo análises das respectivas equações que fornecem as respostas, até que um consenso fosse obtido. Deve-se ressaltar que esse procedimento de identificação e discussão dos problemas na questão 3 contribuiu para aumentar o número de acertos na questão 4, cujo conteúdo era relacionado. O mesmo ocorreu nas questões 5 e 6 , demonstrando a importância da constatação imediata de problemas de aprendizagem dos estudantes.

\section{Considerações Finais}

Este trabalho demonstrou que o uso de tecnologias atuais pode colaborar de maneira significativa para obtenção de melhores resultados durante o processo de ensino e aprendizagem de forma geral. Uma das principais limitações observadas durante a utilização do aplicativo foi em relação à sua dependência de conexão estável com a internet para que as respostas dos alunos pudessem ser enviadas e, consequentemente, os dados serem sincronizados para análises pelo professor. Como trabalho futuro para contornar essa limitação, as respostas serão armazenadas no próprio dispositivo e, em caso de ausência de conexão, suas respostas ficarão aguardando o restabelecimento da conexão para o envio automático e a sincronização dos dados de toda a sala pelo professor.

\section{Referências}

jQuery (2016). Jquery mobile about@ ONLINE.

Martyn, M. (2007). Clickers in the classroom: An active learning approach. Educause quarterly, 30(2):71.

Mercado, L. P. L. (2002). Novas tecnologias na educação: reflexões sobre a prática. UFAL.

Mysql (2016). Mysql about@ ONLINE. 